\title{
Altered Nucleus Accumbens Circuitry Mediates Pain-Induced Antinociception in Morphine-Tolerant Rats
}

\author{
Brian L. Schmidt ${ }^{1,2,3}$ Claudia H. Tambeli, ${ }^{2,3,7}$ Justine Barletta, ${ }^{2,3}$ Lei Luo,, ${ }^{2,3}$ Paul Green,, ${ }^{2,3}$ Jon D. Levine, ${ }^{2,3,4,5,6}$ \\ and Robert W. Gear ${ }^{2,3}$ \\ ${ }^{1}$ Graduate Program in Oral Biology, ${ }^{2}$ Department of Oral and Maxillofacial Surgery, ${ }^{3}$ National Institutes of Health Pain \\ Center (University of California at San Francisco), Departments of ${ }^{4}$ Anatomy and ${ }^{5} \mathrm{Medicine}$, and ${ }^{6}$ Division of Neuroscience, \\ University of California, San Francisco, California 94143, and ${ }^{7}$ Faculty of Dentistry of Piracicaba, University of Campinas, \\ Campinas, Brazil, 13414900
}

We investigated the effect of chronic administration of morphine on noxious stimulus-induced antinociception (NSIA) produced by intraplantar capsaicin injection. In the untreated (naïve) rat, we previously found that NSIA depends on activation of dopamine, nicotinic acetylcholine, and $\mu$ - and $\delta$-opioid receptors in nucleus accumbens. Rats chronically implanted with subcutaneous morphine pellets demonstrated tolerance to the antinociceptive effects of acute systemic morphine administration but did not show cross-tolerance to NSIA. Morphine pretreatment, however, significantly reduced NSIA dependence on intra-accumbens opioid receptors but not on dopamine or nicotinic acetylcholine receptors. As observed in naïve rats, intra-accumbens microinjection of either the dopamine receptor antagonist flupentixol or the nicotinic receptor antagonist mecamylamine blocked NSIA in rats tolerant to the antinociceptive effects of morphine, but, in contrast to naïve rats, intra-accumbens microinjection of either the $\mu$-receptor an- tagonist Cys ${ }^{2}$, Tyr $^{3}$, Orn $^{5}$, Pen $^{7}$ amide or the $\delta$-receptor antagonist naltrindole failed to block NSIA. These findings suggest that although NSIA is dependent on nucleus accumbens opioid receptors in the naïve state, this dependence disappears in rats tolerant to the antinociceptive effects of morphine, which may account for the lack of NSIA cross-tolerance. In separate experiments, intraaccumbens extracellular dopamine levels were measured using microdialysis. Dopamine levels increased after either capsaicin or systemic morphine administration in naïve rats but only after capsaicin administration in morphine pretreated rats. Thus, intraaccumbens dopamine release paralleled antinociceptive responses in naïve and morphine pretreated rats.

Key words: nucleus accumbens; morphine; tolerance; antinociception; dopamine release; noxious stimulation; capsaicin; pain; analgesia; $\mu$ opioid receptors; $\delta$ opioid receptors; microdialysis; jaw-opening reflex
Evidence is accumulating that nucleus accumbens is an important neural substrate for opioid-mediated pain modulation. For example, we recently demonstrated that noxious stimuli can induce antinociception (NSIA) similar in magnitude to that induced by high-dose morphine and that this effect is blocked by intraaccumbens injection of either the nonselective opioid antagonist naloxone (Gear et al., 1999) or by a selective antagonist for either $\mu$ - or $\delta$-opioid receptors (Schmidt et al., 2002). Direct microinjection of opioids into nucleus accumbens also induces antinociception (Dill and Costa, 1977; Yu and Han, 1990; Schmidt et al., 2002), and the antinociceptive effect of systemically administered morphine can be attenuated by intra-accumbens naloxone administration (Dill and Costa, 1977).

Non-opioid receptors in nucleus accumbens play a role in antinociception as well. For example, intra-accumbens injection of the nicotinic acetylcholine receptor antagonist mecamylamine

Received Feb. 14, 2002; revised April 29, 2002; accepted May 8, 2002.

This work was supported by the State of California Tobacco Related Diseases Research program, United States Public Health Service National Institute of Dental and Craniofacial Research, Grant K16 DE00386 to B.L.S., and by a post-doctoral fellowship to C.H.T. from Conselho Nacional de Desenvolvimento Cientifico e Tecnologico, Brazil. We are grateful to Dr. David Reichling (University of California at San Francisco) and to Dr. Carl-Olav Stiller (Karolinska Hospital, Stockholm) for many helpful discussions during the course of this work.

Correspondence should be addressed to Dr. Robert W. Gear, National Institutes of Health Pain Center (UCSF), C-522 (Box 0440), University of California at San Francisco, San Francisco, CA 94143-0440. E-mail: rwg@itsa.ucsf.edu.

Copyright (C) 2002 Society for Neuroscience $0270-6474 / 02 / 226773-08 \$ 15.00 / 0$ blocks NSIA and also inhibits the antinociceptive effect of systemically administered morphine (Schmidt et al., 2001). Dopaminergic mechanisms have also been implicated in nociceptive modulation (Altier and Stewart, 1999). Intra-accumbens microinjection of a dopamine antagonist blocks NSIA (Gear et al., 1999) as well as the antinociceptive effect of intraventral tegmental area morphine (Altier and Stewart, 1998).

In the current study we investigated the effect of chronic morphine administration on NSIA. Opioid tolerance is a well known phenomenon that results from chronic exposure to an opioid agonist such as morphine (Harrison et al., 1998; Borgland, 2001; Williams et al., 2001). Tolerance induced by exposure to an agonist can produce cross-tolerance to a different agonist that acts at the same receptors. Morphine and heroin, both of which act at $\mu$-receptors, can produce cross-tolerance to each other, and effects mediated by endogenous opioids can also become crosstolerant to exogenous opioids (Lewis et al., 1981; Christie et al., 1982; Girardot and Holloway, 1984). Because NSIA depends on intra-accumbens opioid receptors, we tested the hypothesis that rats tolerant to the antinociceptive effects of morphine would exhibit cross-tolerance to NSIA.

Other goals of this study were to evaluate the response of nucleus accumbens dopamine levels to noxious stimulation or to acute morphine administration in naïve rats and in rats tolerant to antinociceptive effects of morphine, and to determine whether tolerance alters the requirement for dopaminergic and nicotinic neurotransmission in NSIA. 


\section{MATERIALS AND METHODS}

Animals. Experiments were performed on 280-380 gm male Sprague Dawley rats (Bantin and Kingman, Fremont, CA). These animals were housed in groups of two per cage under a $12 \mathrm{hr}$ light/dark cycle (lights on at 7:00 A.M.) in the animal care facility of the University of California, San Francisco. Food and water were available ad libitum. Experimental protocols were approved by the University Committee on Animal Research.

Nociceptive assay. Changes in nociception were measured as attenuation (i.e., antinociception) or enhancement (i.e., hyperalgesia) of the trigeminal jaw-opening reflex (JOR) electromyographic (EMG) signal (Mason et al., 1985; Gear and Levine, 1995; Gear et al., 1999; Schmidt et al., 2001). This assay was chosen because it is segmentally remote from the site at which the noxious stimulus is applied in the hindpaw, thus allowing separation of heterosegmental effects from any intrasegmental effects that might influence assays such as the paw withdrawal reflex or the tail flick reflex. Although the rats were anesthetized in this study, we have shown that NSIA occurs in the awake animal (Gear et al., 1999). In groups of awake rats, capsaicin administered into the fore paw significantly increased hindpaw withdrawal thresholds, indicating antinociception, and this effect was blocked by intra-accumbens administration of either the dopamine receptor antagonist flupentixol or the opioid receptor antagonist naloxone.

Morphine tolerance protocol. Antinociceptive tolerance to morphine was induced by subcutaneous implantation of two morphine base pellets (75 mg; National Institute on Drug Abuse) (Gold et al., 1994). The antinociceptive action of two morphine pellets, as measured by tail flick latency, returns to baseline value by 12-36 hr (Yoburn et al., 1985; Gold et al., 1994). Implantation of pellets was performed under isoflurane anesthesia (Abbott Laboratories, Chicago, IL). Experiments were performed $72 \mathrm{hr}$ after pellet implantation. Vehicle pellets (from the same source) were similarly implanted in one group.

Anesthesia. All experiments were performed in rats anesthetized with an intraperitoneal injection of urethane $(0.9 \mathrm{gm} / \mathrm{kg})$ and $\alpha$-chloralose (45 $\mathrm{mg} / \mathrm{kg}$; both from Sigma-Aldrich, St. Louis, MO). This method provides a stable level of anesthesia (Buelke-Sam et al., 1978) and JOR EMG signal over the time period required to complete the experiments (Gear and Levine, 1995).

Electrode implantation. To evoke the JOR, a bipolar stimulating electrode, consisting of two insulated copper wires (36 AWG), each with 0.2 $\mathrm{mm}$ of insulation removed from the tip, one tip extending $2 \mathrm{~mm}$ beyond the other, was inserted into the pulp of a mandibular incisor to a depth of $22 \mathrm{~mm}$ from the incisal edge of the tooth to the tip of the longest wire and cemented into place with dental composite resin (Citrix, Golden Gate Dental Supply, South San Francisco, CA). A bipolar recording electrode, consisting of two wires of the same material as the stimulating electrode with $4 \mathrm{~mm}$ of insulation removed, was inserted into the anterior belly of the digastric muscle ipsilateral to the implanted tooth to a depth sufficient to completely submerge the uninsulated end of the wire.

JOR electromyogram. At the beginning of each experiment, stimulation current was set at three times the threshold for eliciting a JOR. Each data point consisted of the average peak-to-peak amplitude of 12 consecutive jaw-opening reflex EMG signals evoked by stimulating the tooth pulp with $0.2 \mathrm{msec}$ square wave pulses at a frequency of $0.33 \mathrm{~Hz}$. Baseline amplitude was defined as the average of the last three data points, recorded at $5 \mathrm{~min}$ intervals, before an experimental intervention. As is customary for JOR studies (Chiang et al., 1990, 1991; Banks et al., 1992; Gear and Levine, 1995; Ahn et al., 1998; Takeda et al., 1998; Zhang et al., 1998; Gear et al., 1999; Zhang et al., 1999; Belforte et al., 2001; Schmidt et al., 2001), data were normalized for differences in baseline by calculating the percentage change from baseline for each postintervention data point. These values were plotted in the figures and used in the statistical analyses.

Cannula placement. For nucleus accumbens injections, 23 gauge stainless steel guide cannulas were stereotactically positioned bilaterally and cemented with orthodontic resin (L. D. Caulk Co., Milford, DE) to allow injections via insertion of a 30 gauge stainless steel injection cannula, which extended $2 \mathrm{~mm}$ beyond the guide cannulas, connected to a $2 \mu \mathrm{l}$ microsyringe (Hamilton, Reno, NV). Injection volumes were $0.5 \mu \mathrm{l}$ in all experiments and were performed over a period of $120 \mathrm{sec}$; the injection cannula was left in place for an additional $30 \mathrm{sec}$. The stereotaxic coordinates for nucleus accumbens injections were (from bregma) 1.3 $\mathrm{mm}$ rostral, $7.2 \mathrm{~mm}$ ventral, and $\pm 1.8 \mathrm{~mm}$ lateral. Injection sites were verified by histological examination $(100 \mu \mathrm{m}$ sections stained with cresyl

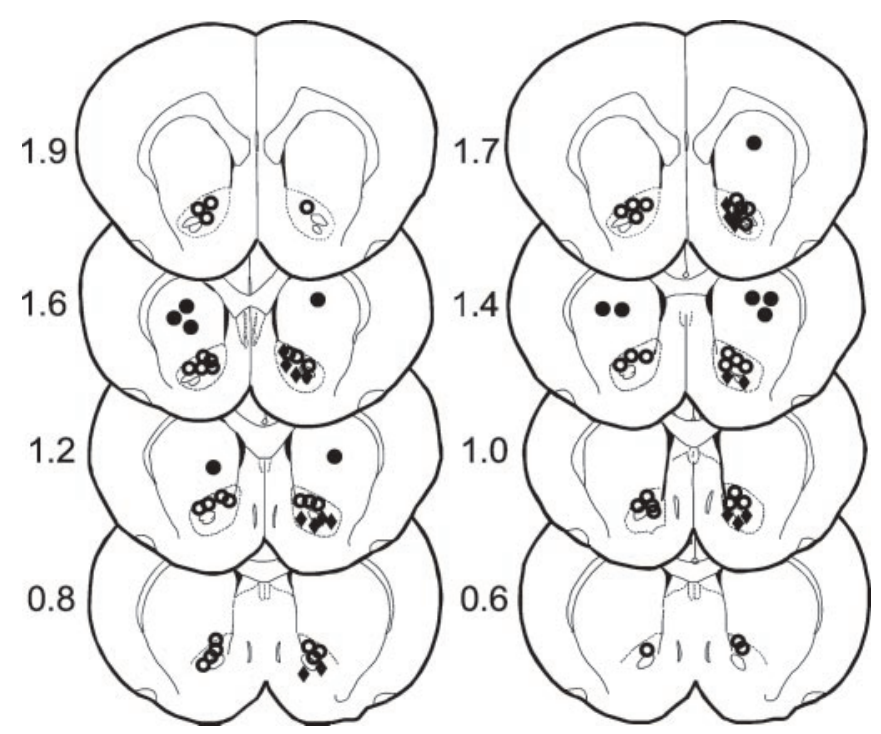

Figure 1. Location of injections. Open circles are considered to be within the target area of nucleus accumbens; note that they mostly fall within the area of the core. Filled circles designate offsite injections. Filled diamonds designate microdialysis probe location. Because some injections were mapped to identical locations, there are fewer symbols shown than the total number of injections performed.

violet acetate) and plotted on coronal sections adapted from the atlas of Paxinos and Watson (1986) (Fig. 1).

In vivo microdialysis. Seventy-two hours before each experiment, a 12 $\mathrm{mm}, 21$ gauge guide cannula was stereotactically positioned and cemented with orthodontic resin (L. D. Caulk Co.) into the right nucleus accumbens: (from bregma) $1.3 \mathrm{~mm}$ rostral, $7.2 \mathrm{~mm}$ ventral, and $1.8 \mathrm{~mm}$ lateral. For this procedure rats were anesthetized with pentobarbital sodium, $50 \mathrm{mg} / \mathrm{kg}$ (Abbott Laboratories, North Chicago, 60064). On the day of the experiment, rats were anesthetized with the $\alpha$-chloralose/ urethane combination, and a CMA/11 microdialysis probe (CMA/Microdialysis AB, Stockholm, Sweden) was inserted through the guide cannula such that the $2 \mathrm{~mm}$ active membrane extended beyond the tip of the cannula. The microdialysis perfusate consisted of artificial CSF (148 $\mathrm{mm} \mathrm{NaCl}, 1.2 \mathrm{~mm} \mathrm{CaCl}_{2}, 2.7 \mathrm{~mm} \mathrm{KCl}, 0.85 \mathrm{~mm} \mathrm{MgCl}_{2}, \mathrm{pH}$ 7.4). The flow rate was set at $2 \mu \mathrm{l} / \mathrm{min}$ with a CMA/102 microdialysis pump (CMA/ Microdialysis AB). After a $2 \mathrm{hr}$ equilibration period, six baseline fractions were collected at 10 min intervals. The mean basal dopamine levels for naïve and morphine pretreated rats were 0.400 and $0.454 \mathrm{ng} / \mathrm{ml}$, respectively, which were not significantly different $(t(61)=-0.352 ; p=$ 0.726). The experimental interventions were then performed, and dialysis samples were collected every $10 \mathrm{~min}$ and analyzed for dopamine using HPLC.

HPLC analysis. Dopamine was measured by HPLC using electrochemical detection. Dopamine was isolated by injecting dialysate samples with a CMA/200 microsampler (CMA/Microdialysis AB) through a $150 \times 3$ mm column (ESA, MD-150, Chelmsford, MA). Dopamine was quantified by an ESA Coulochem II detector and an analytical cell (ESA model 5011) with two electrodes in series: an oxidizing electrode $(+220 \mathrm{mV})$ and a reducing electrode $(-60 \mathrm{mV})$. The mobile phase consisted of 75 mM sodium phosphate, $1.7 \mathrm{~mm}$ 1-octanesulfonic acid, $100 \mu \mathrm{l} / 1$ triethylamine, $25 \mu \mathrm{M}$ EDTA, and $10 \%$ acetonitrile; the $\mathrm{pH}$ was adjusted to 3.0 with phosphoric acid. The flow rate was pumped at a rate of $0.4 \mathrm{ml} / \mathrm{min}$ with a Shimadzu LC-10ADVP (Shimadzu Corporation, Kyoto, Japan).

Drugs and doses. Capsaicin was dissolved in Tween $80(50 \%)$ and ethanol $(50 \%)$ to an initial concentration of $50 \mu \mathrm{g} / \mu \mathrm{l}$ and diluted with $0.9 \%$ saline to a concentration of $5 \mu \mathrm{g} / \mu \mathrm{l}$; subdermal capsaicin injection volume was $50 \mu \mathrm{l}(250 \mu \mathrm{g})$ in all experiments. $\mathrm{Cys}^{2}, \mathrm{Tyr}^{3}, \mathrm{Orn}^{5}, \mathrm{Pen}^{7}$ amide (CTOP) $1 \mu \mathrm{g}$ (Ableitner and Schulz, 1992; Devine et al., 1993; Badiani et al., 1995) was dissolved in PBS. Naltrindole $1 \mu \mathrm{g}$ (Kelley et al., 1996), (R)-(+)-7-Chloro-8-hydroxy-3-methyl-1-phenyl-2,3,4,5-tetrahydro1H-3-benzazepine (SCH-23390) (Caine et al., 1995; Moses et al., 1995; Okamura et al., 1997) and nor-binaltorphimine dihydrochloride $1.8 \mu \mathrm{g}$ (Bodnar et al., 1995; Kelley et al., 1996) were dissolved in distilled water. 
All drugs and reagents were obtained from Sigma-Aldrich or from Sigma-RBI (Natick, MA).

Because it has been reported that nor-binaltorphimine may not be selective for $\kappa$-opioid receptors until several hours after administration (Horan et al., 1992; Spanagel et al., 1994; Wettstein and Grouhel, 1996), intranucleus accumbens cannulas were placed under pentobarbital anesthesia, and nor-binaltorphimine was administered $1 \mathrm{~d}$ before the experiment. On the day of the experiment, the rats were anesthetized with $\alpha$-chloralose/urethane, and the usual experimental protocols were followed.

Data analysis. A two-way repeated measures ANOVA with one between-subjects factor (i.e., treatment) and one within-subjects factor (i.e., time) was used to determine whether there were significant $(p>$ 0.05 ) differences in responses (expressed as percentage change from baseline) among the groups. For each ANOVA, the Mauchley criterion was used to determine whether the assumption of sphericity for the within-subjects effects was met; if the Mauchley criterion was not satisfied, Greenhouse-Geisser-adjusted $p$ values are presented. If there was a significant between-subjects main effect of treatment group, post hoc contrasts, using the Tukey test, were performed to determine the basis of the significant difference.

\section{RESULTS}

\section{Morphine tolerance}

Although the protocol that we used to induce antinociceptive tolerance to morphine is well established, we compared the antinociceptive effect of morphine $(10 \mathrm{mg} / \mathrm{kg})$ in rats chronically exposed to morphine (see Materials and Methods) and previously untreated (i.e., "naïve") as well as sham treated (i.e., implantation of vehicle pellets) rats (Fig. 2) (all statistical results are shown in Table 1). The difference in antinociception between these groups was highly significant, confirming that pretreatment with morphine pellets, but not with vehicle pellets, induces tolerance to the antinociceptive effects of high-dose morphine.

\section{NSIA in morphine-tolerant rats}

We also compared the antinociceptive effect of subdermally administered capsaicin $(250 \mu \mathrm{g})$ into the plantar surface of a hindpaw in morphine-tolerant rats and naïve rats. The antinociceptive effect of this treatment was not significantly different in these two groups, indicating that chronic morphine treatment does not produce cross-tolerance to NSIA (Fig. 3).

\section{Involvement of nucleus accumbens opioid receptors}

We previously observed in naïve rats that NSIA is mediated in nucleus accumbens by both $\mu$ - and $\delta$ - but not $\kappa$-opioid receptors (Schmidt et al., 2002). To determine whether this is the case in rats tolerant to the antinociceptive effects of morphine, we administered either CTOP or naltrindole, selective antagonists for $\mu$ - and $\delta$-opioid receptors, respectively, to nucleus accumbens 10 min before the administration of intraplantar capsaicin. The long-lasting selective $\kappa$-receptor antagonist nor-binaltorphimine was administered the day before the experiment to avoid the nonselective action that is reported to occur after acute administration (see Materials and Methods). The antinociceptive effect of capsaicin after these antagonists was not significantly different from its effect when administered alone (Fig. 4). Thus, although NSIA is unchanged in rats tolerant to the antinociceptive effects of morphine, this form of antinociception does not depend on nucleus accumbens opioid receptors as is the case in morphine naïve rats. Neither CTOP nor naltrindole administered alone into nucleus accumbens (i.e., without subsequent capsaicin administration) affected the JOR (data not shown).

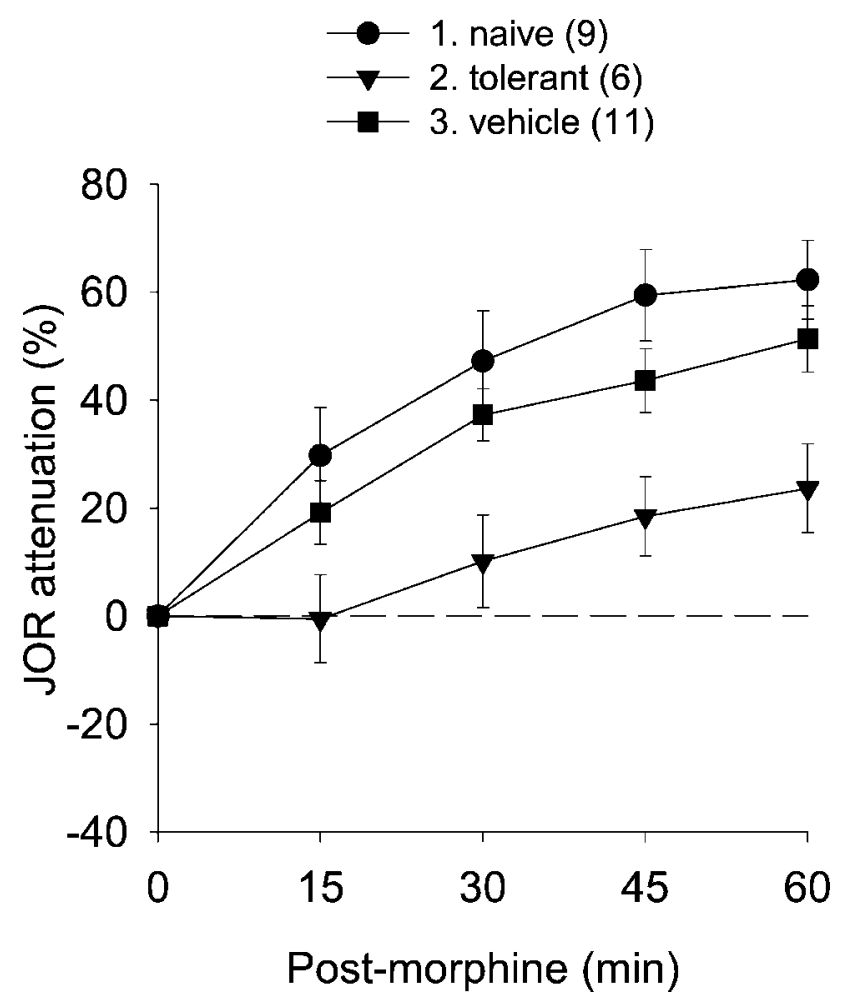

Figure 2. The antinociceptive effect of acute subcutaneous morphine administration in naïve rats and in rats pretreated with either morphine or vehicle pellets. The ability of pretreatment protocol using morphine pellets to induce tolerance is indicated by the virtually complete disappearance of antinociception after acute morphine administration. In this and subsequent figures, antinociception is plotted as percentage attenuation from baseline of the JOR EMG amplitude on the $y$-axis (i.e., greater antinociception is represented as higher positive numbers). Baseline JOR recordings were obtained before interventions. Time 0 on the $x$-axis represents the time at which the last (or only) treatment was given for each group. Data are plotted as mean \pm SEM. The number of rats in each group is shown in parentheses. Group numbers, preceding group names, refer to the Tukey post hoc analyses in Table 1.

\section{Involvement of nucleus accumbens dopamine and nicotinic cholinergic receptors}

Lack of participation by nucleus accumbens opioid receptors in NSIA in rats tolerant to the antinociceptive effects of morphine could indicate either that nucleus accumbens itself no longer plays a role in this phenomenon or that intra-accumbens circuits are reorganized to eliminate dependence on opioid receptors. To distinguish between these possibilities, we tested whether NSIA in morphine pretreated rats is dependent on either dopamine or acetylcholine nicotinic receptors in nucleus accumbens as was shown previously to be the case in naïve rats (Gear et al., 1999; Schmidt et al., 2001). Intra-accumbens administration, but not offsite administration, of the selective $\mathrm{D}_{1}$-receptor antagonist SCH-23390 10 min before intraplantar capsaicin blocked NSIA; intra-accumbens administration of the nonselective dopamine antagonist flupentixol, which has been tested previously in naïve rats, also blocked NSIA (Fig. 5a). Intra-accumbens administration, but not offsite administration, of the acetylcholine nicotinic receptor antagonist mecamylamine $10 \mathrm{~min}$ before intraplantar capsaicin also blocked NSIA (Fig. 5b), as was observed previously in naïve rats (Schmidt et al., 2001). These results indicate that although opioid receptors are no longer involved, nucleus accumbens itself is still an important neural substrate for NSIA. We also 
Table 1. Statistical summary

\begin{tabular}{|c|c|c|c|c|c|c|}
\hline & \multicolumn{4}{|l|}{ ANOVAs } & \multicolumn{2}{|c|}{ Tukey post hoc } \\
\hline & Effects & DF & $F$ & $p$ & Groups & $p$ \\
\hline \multirow[t]{3}{*}{ Figure 2} & $\mathrm{Tx}$ & 1,23 & 6.442 & 0.006 & 1 versus 2 & 0.004 \\
\hline & Time & 3,69 & 34.764 & $<0.001$ & 1 versus 3 & 0.384 \\
\hline & Time $\times \mathrm{tx}$ & 6,69 & 0.444 & 0.778 & 2 versus 3 & 0.049 \\
\hline \multirow[t]{3}{*}{ Figure 3} & $\mathrm{Tx}$ & 1,20 & 0.740 & 0.400 & & \\
\hline & Time & 3,60 & 0.944 & 0.393 & $\mathrm{n} / \mathrm{a}^{*}$ & \\
\hline & Time $\times \mathrm{tx}$ & 3,60 & 0.143 & 0.854 & & \\
\hline \multirow[t]{3}{*}{ Figure 4} & $\mathrm{Tx}$ & 3,32 & 1.139 & 0.348 & & \\
\hline & Time & 3,96 & 6.040 & 0.004 & $\mathrm{n} / \mathrm{a}^{*}$ & \\
\hline & Time $\times \mathrm{tx}$ & 9,96 & 1.413 & 0.224 & & \\
\hline \multirow[t]{6}{*}{ Figure $5 a$} & & & & & 1 versus 2 & 0.016 \\
\hline & & & & & 1 versus 3 & 0.006 \\
\hline & $\mathrm{Tx}$ & 3,24 & 6.614 & 0.002 & 1 versus 4 & 0.967 \\
\hline & Time & 3,72 & 0.063 & 0.951 & 2 versus 3 & 0.833 \\
\hline & Time $\times \mathrm{tx}$ & 9,72 & 1.160 & 0.941 & 2 versus 4 & 0.133 \\
\hline & & & & & 3 versus 4 & 0.045 \\
\hline \multirow[t]{3}{*}{ Figure $5 b$} & $\mathrm{Tx}$ & 2,20 & 7.626 & 0.003 & 1 versus 2 & 0.003 \\
\hline & Time & 3,60 & 9.781 & $<0.001$ & 1 versus 3 & 0.642 \\
\hline & Time $\times \mathrm{tx}$ & 6,60 & 1.084 & 0.379 & 2 versus 3 & 0.021 \\
\hline \multirow[t]{3}{*}{ Figure $5 c$} & $\mathrm{Tx}$ & 2,19 & 31.321 & $<0.001$ & 1 versus 2 & $<0.001$ \\
\hline & Time & 3,57 & 0.229 & 0.732 & 1 versus 3 & $<0.001$ \\
\hline & Time $\times \mathrm{tx}$ & 6,57 & 0.571 & 0.638 & 2 versus 3 & 0.959 \\
\hline \multirow[t]{3}{*}{ Figure 6 (DA) } & $\mathrm{Tx}$ & 1,12 & 0.486 & 0.499 & & \\
\hline & Time & 5,60 & 3.379 & 0.040 & $\mathrm{n} / \mathrm{a}^{*}$ & \\
\hline & Time $\times \mathrm{tx}$ & 5,60 & 3.133 & 0.050 & & \\
\hline \multirow[t]{3}{*}{ Figure 6 (JOR) } & $\mathrm{Tx}$ & 1,7 & 0.018 & 0.896 & & \\
\hline & Time & 5,35 & 1.528 & 0.249 & $\mathrm{n} / \mathrm{a}^{*}$ & \\
\hline & Time $\times \mathrm{tx}$ & 5,35 & 0.095 & 0.192 & & \\
\hline \multirow[t]{3}{*}{ Figure 7 (DA) } & $\mathrm{Tx}$ & 1,9 & 16.512 & 0.003 & & \\
\hline & Time & 5,45 & 2.195 & 0.161 & $\mathrm{n} / \mathrm{a}^{*}$ & \\
\hline & Time $\times \mathrm{tx}$ & 5,45 & 2.344 & 0.147 & & \\
\hline \multirow[t]{3}{*}{ Figure 7 (JOR) } & $\mathrm{Tx}$ & 1,9 & 42.717 & $<0.001$ & & \\
\hline & Time & 5,45 & 0.900 & 0.431 & $\mathrm{n} / \mathrm{a}^{*}$ & \\
\hline & Time $\times \mathrm{tx}$ & 5,45 & 0.402 & 0.693 & & \\
\hline
\end{tabular}

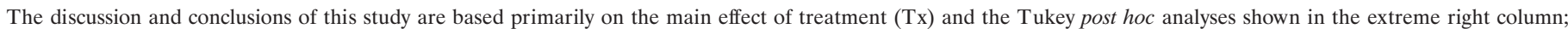

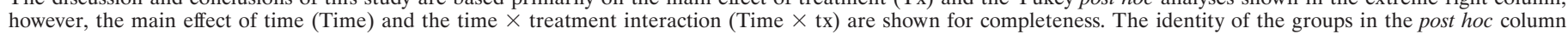

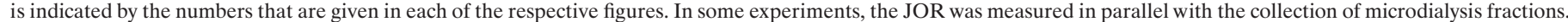

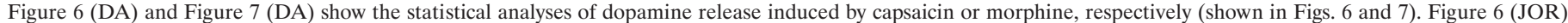

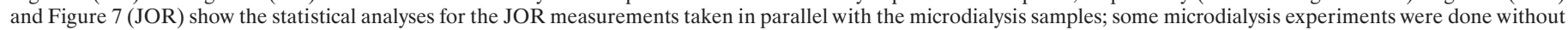
simultaneous JOR measurements. See Figures 2 and 3 for the effect of morphine or capsaicin, respectively, on the JOR in morphine naïve and tolerant rats.

*Post hoc analyses were not done because there were only two groups or because there was no significant main effect of treatment (i.e., Fig. 4).

confirmed the ability of SCH-23390 to block NSIA in naïve rats (Fig. 5c).

\section{Noxious stimulation and nucleus accumbens dopamine levels}

Because NSIA is dependent on intra-accumbens dopamine receptors in both morphine naïve and morphine pretreated rats, we performed microdialysis experiments to measure the effect of capsaicin administration $(250 \mu \mathrm{g})$ on nucleus accumbens dopamine release. To correlate the effect of capsaicin on nucleus accumbens dopamine levels with its effect on nociceptive responses, the JOR was measured simultaneously in some experiments. Intra-accumbens dopamine levels increased after capsaicin injection in both groups (Fig. 6). Although there appeared to be a spike of dopamine in the naive group at the 20 min time point (that likely accounts for the significant time $\times$ treatment interaction) (Table 1), the overall effect of capsaicin on dopamine was not significantly different, however, between the two groups. Similarly, the antinociceptive effect of capsaicin in these two groups was not significantly different (Table 1), confirming the finding shown in Figure 3. Taken together, these findings support the suggestion that NSIA induces dopamine release in nucleus accumbens and that this release correlates closely with antinociception.

\section{Systemic morphine and nucleus accumbens dopamine levels}

The effect of subcutaneous injection of morphine $(10 \mathrm{mg} / \mathrm{kg})$ on nucleus accumbens dopamine release in rats tolerant to the antinociceptive effects of morphine and naïve rats was assessed in experiments parallel to those above with capsaicin. Morphine induced antinociception as well as increased intra-accumbens dopamine levels in naïve rats but did not induce either effect in rats tolerant to the antinociceptive effects of morphine (Fig. 7, 


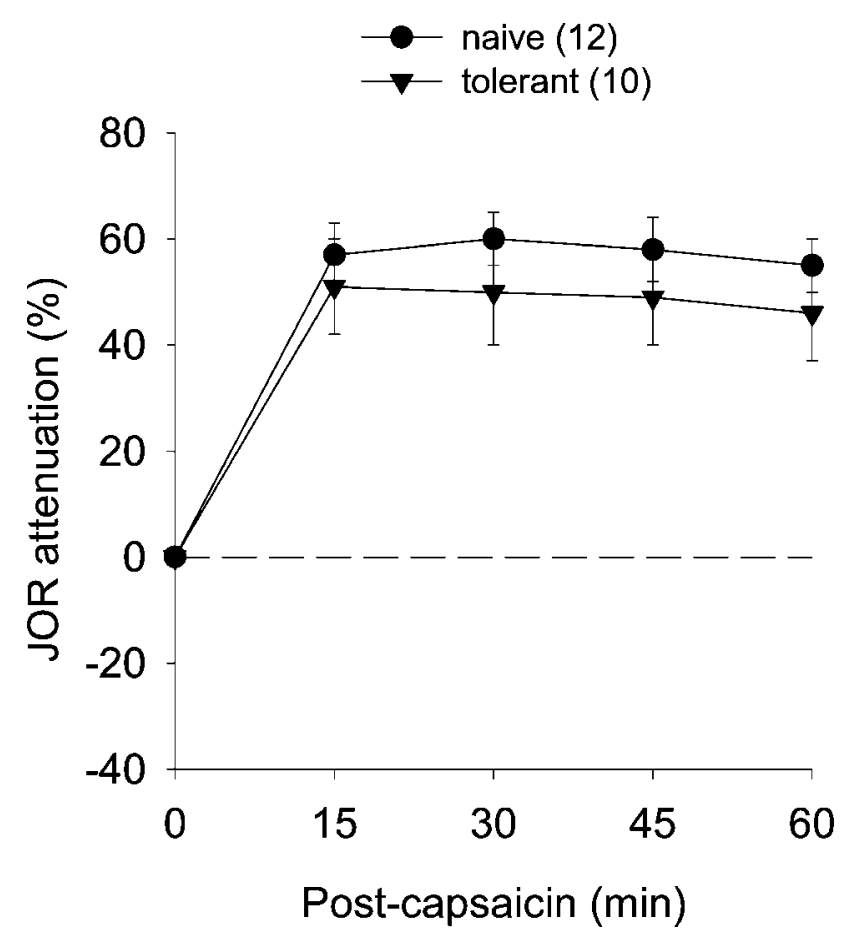

Figure 3. The antinociceptive effect of intraplantar capsaicin administration in morphine-tolerant and naïve rats. Absence of cross-tolerance is indicated by the ability of capsaicin to induce a similar degree of antinociception in naïve and morphine-tolerant rats.

Table 1), thus further supporting the suggestion that dopamine release in nucleus accumbens correlates with the antinociceptive effect.

\section{DISCUSSION}

In the naïve rat, intra-accumbens administration of either a selective $\mu$ - or $\delta$-opioid receptor antagonist blocks NSIA, but antinociception induced by direct intra-accumbens administration of opioid agonists requires both $\mu$ - and $\delta$-agonists in combination (Schmidt et al., 2002). These results strongly support the dependence of NSIA on nucleus accumbens opioid receptors in the naïve rat and also suggest that to induce antinociception, $\mu$ - and $\delta$-opioid receptors must act cooperatively as suggested by other studies (Porreca et al., 1987; Heyman et al., 1989; Negri et al., 1995; Loh et al., 1998; Matthes et al., 1998). Despite opioid receptor dependence of NSIA in the naïve state, NSIA is undiminished in rats that are tolerant to the antinociceptive effects of morphine, implying lack of cross-tolerance. Thus, unlike the naïve rat, NSIA was not blocked in morphine-tolerant rats by intra-accumbens administration of either $\mu$ - or $\delta$-opioid receptor antagonists.

Such a switch from dependence on nucleus accumbens $\mu$ - and $\delta$-opioid receptors to independence of these receptors could result either from a change in intra-accumbens NSIA circuitry or from extra-accumbens circuit adaptations that bypass nucleus accumbens altogether. To determine whether nucleus accumbens mediates NSIA in rats tolerant to the antinociceptive effects of morphine, we microinjected antagonists for either nicotinic cholinergic receptors or dopamine receptors, both of which are known to mediate NSIA (Gear et al., 1999; Schmidt et al., 2001). NSIA was blocked by the nicotinic receptor antagonist mecamylamine as well as by the dopamine receptor antagonist flupentixol. In addition, because flupentixol may act at non-

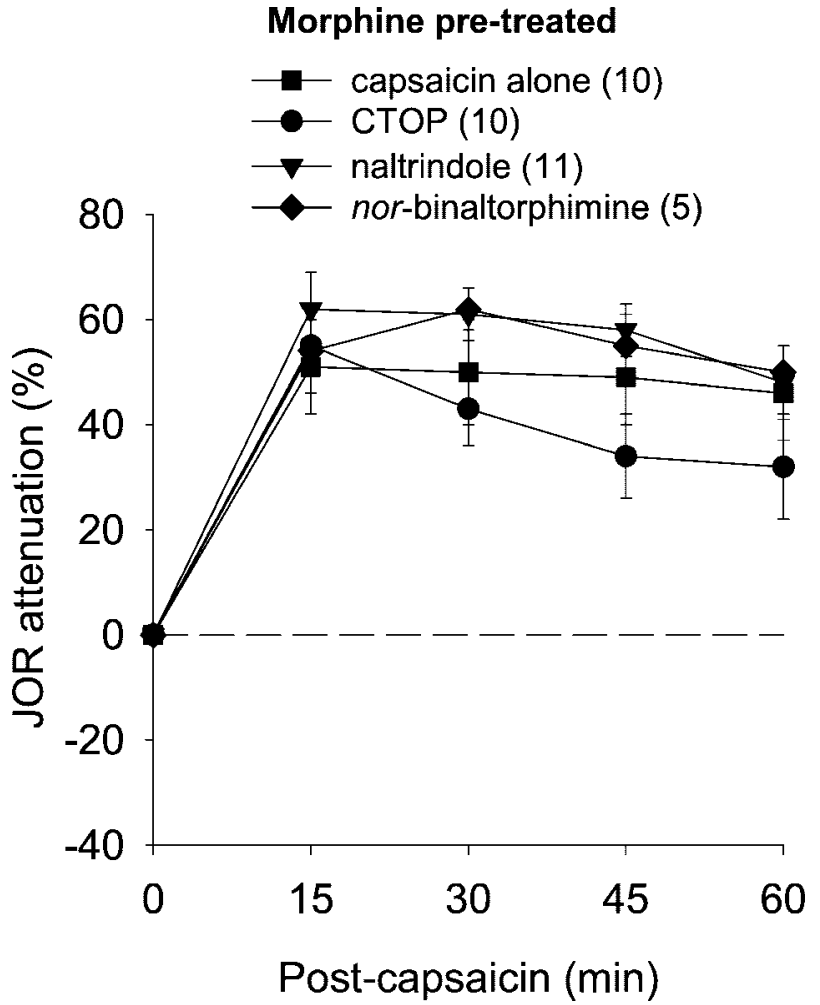

Figure 4. Effect of selective opioid receptor antagonists administered into nucleus accumbens to block the NSIA in morphine pretreated rats. None of these antagonists significantly reduced capsaicin-induced antinociception, indicating lack of participation of opioid receptors in nucleus accumbens in NSIA during morphine tolerance.

dopamine receptors, we administered the $\mathrm{D}_{1}$-receptor selective antagonist SCH-23390, which also blocked NSIA in both naïve and tolerant rats. These results indicate that nucleus accumbens still mediates NSIA in rats chronically exposed to morphine and, of note, bear a striking parallel to our earlier study in which we found that nicotinic receptors no longer mediate NSIA in rats chronically exposed to nicotine (Schmidt et al., 2001). The mechanism(s) by which NSIA is able to switch from opioid receptor dependence to independence in rats chronically exposed to morphine on the one hand, or from nicotinic receptor dependence to independence in rats chronically exposed to nicotine on the other hand, remains to be determined.

Nucleus accumbens dopamine mechanisms appear to be an important underlying feature of NSIA because intra-accumbens administration of a dopamine antagonist blocks NSIA in naïve rats (Gear et al., 1999) as well as in rats chronically exposed to either nicotine (Schmidt et al., 2001) or morphine (this study). We therefore measured intra-accumbens dopamine release in response to administration of either morphine or capsaicin in rats chronically exposed to morphine and in naïve rats. We found that dopamine release qualitatively paralleled the induction of antinociception in these groups. That is, capsaicin induced antinociception as well as dopamine release in rats chronically exposed to morphine as well as in naïve rats, whereas acute morphine (10 $\mathrm{mg} / \mathrm{kg}$ ) administration induced dopamine release and antinociception in naïve rats but not in rats chronically exposed to morphine.

Our finding that acutely administered morphine induced dopamine release in nucleus accumbens in the naïve rat is in 


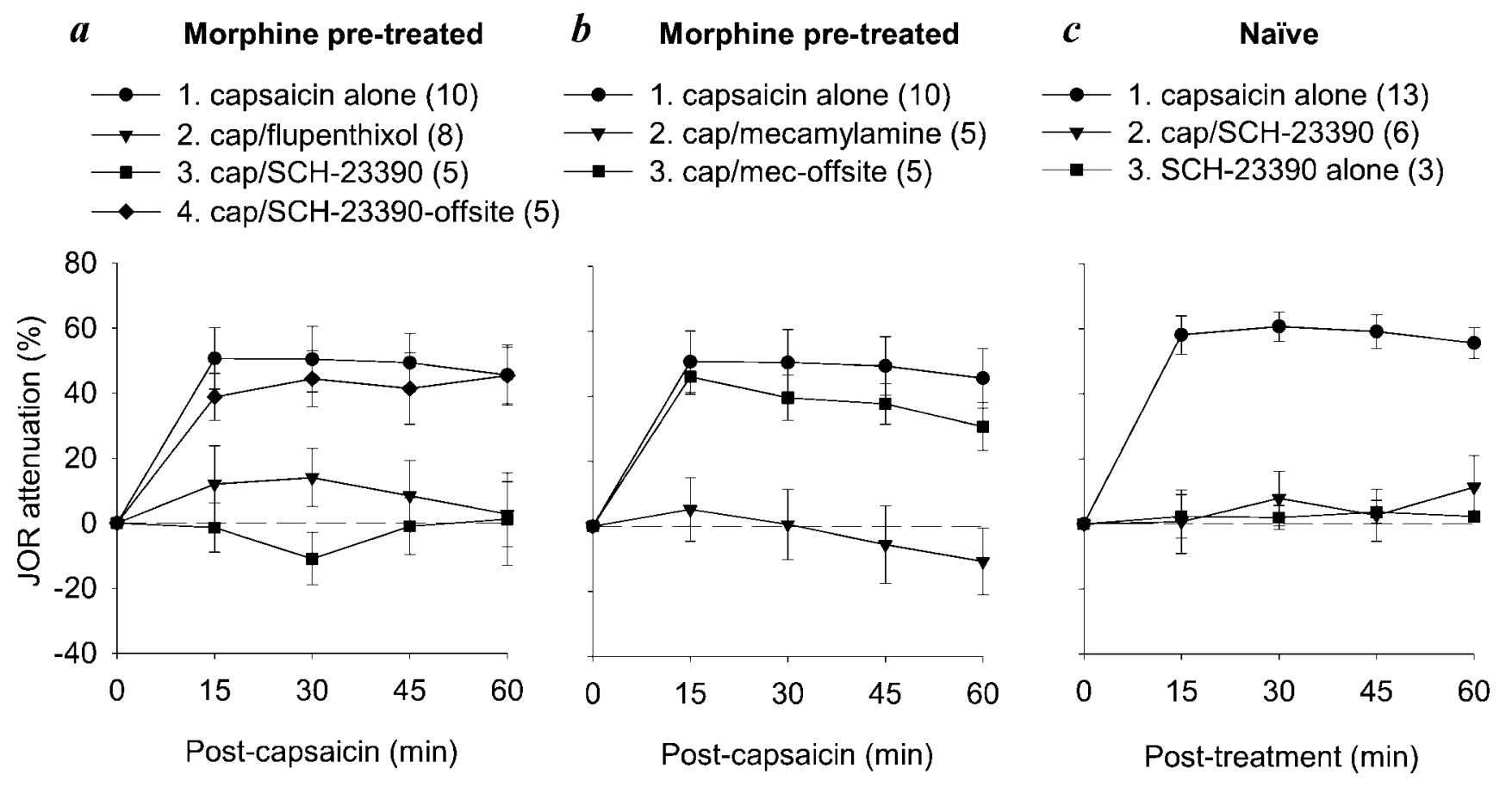

Figure 5. Effect of intra-accumbens administration of non-opioid receptor antagonists on NSIA in morphine pre-treated and naïve rats. $a$, NSIA was blocked by either flupentixol (nonselective dopamine receptor antagonist) or SCH-23390 (selective $\mathrm{D}_{1}$-receptor antagonist) in morphine pretreated rats. $b$, NSIA was blocked by intra-accumbens administration, but not by offsite administration, of the nicotinic receptor antagonist mecamylamine in morphine pretreated rats. $c$, NSIA was blocked by SCH-23390 in naïve rats. SCH-23390 had no effect when administered alone. cap, Capsaicin. Group numbers, preceding group names, refer to the Tukey post hoc analyses in Table 1.

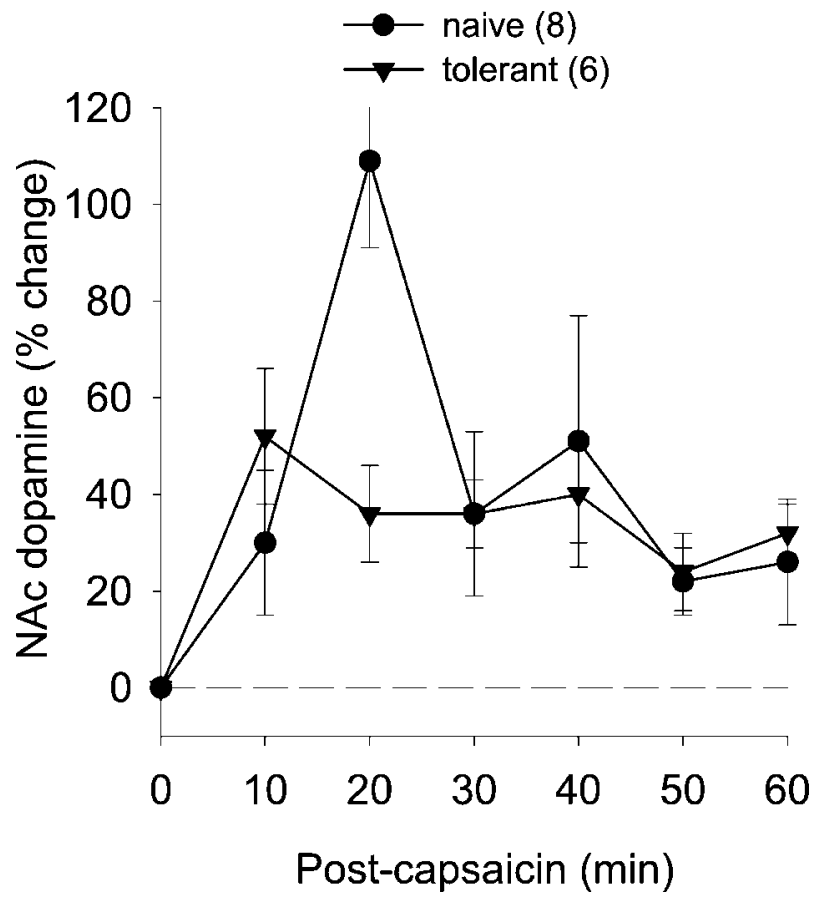

Figure 6. Effect of noxious stimulation on nucleus accumbens dopamine levels in naïve and morphine-tolerant rats. Although there was a spike in dopamine release in naïve rats at the 20 min time point, the overall effect of capsaicin on dopamine release was not significantly different.

agreement with other studies (Pothos et al., 1991; Borg and Taylor, 1997; Maisonneuve et al., 2001), but the observation that chronic morphine abrogated the ability of acute morphine to induce release of dopamine into nucleus accumbens may be

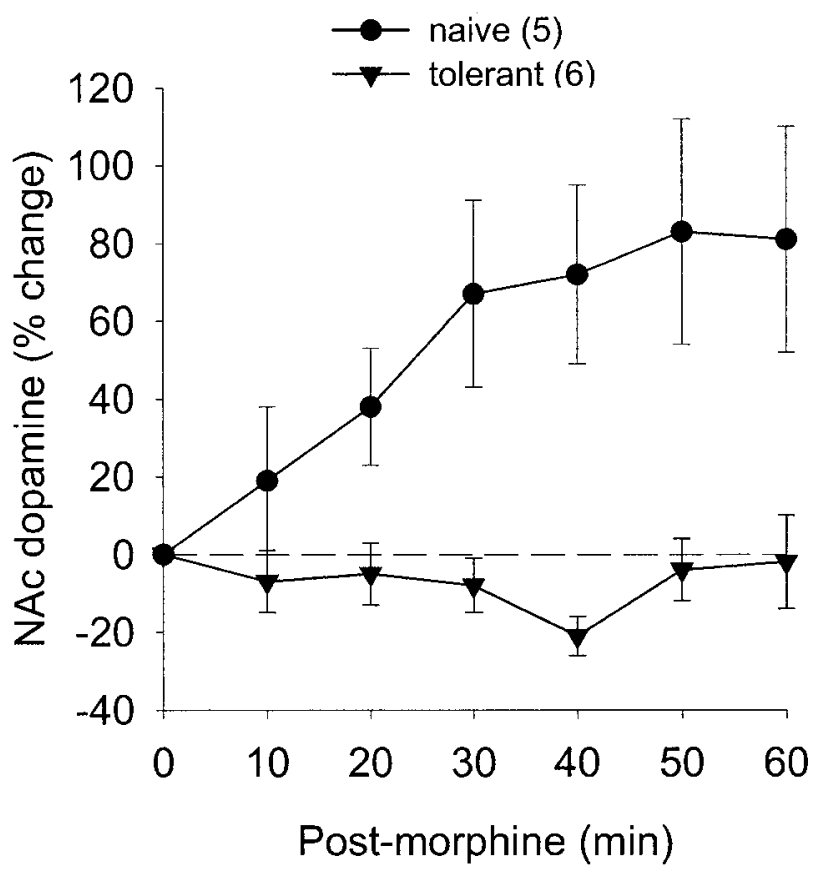

Figure 7. Effect of morphine administration on nucleus accumbens dopamine levels in naïve or morphine-tolerant rats. Morphine induced an increase in dopamine in naïve rats, but neither effect was observed in tolerant rats.

specific to the morphine pellet implantation protocol used in the present study; it was shown that acute morphine injection after seven daily injections of morphine $(20 \mathrm{mg} / \mathrm{kg})$ does not abolish morphine-induced dopamine release in nucleus accumbens 
(Pothos et al., 1991). It has also been shown that naloxoneprecipitated withdrawal in rats chronically implanted with pellets results in a significant decrease in dopamine levels, an effect that requires a high dose of morphine (i.e., $100 \mathrm{mg} / \mathrm{kg}$, an order of magnitude higher than that given in the present study) to overcome (Rossetti et al., 1992).

A number of studies have shown that opioids and dopamine interact in nucleus accumbens in complex ways (for review, see Stinus et al., 1992). Dopamine receptor agonists injected into nucleus accumbens induce behavioral activation as do opioid receptor agonists (for review, see Kalivas et al., 1993), although these appear to be independent actions. However, neurotoxic depletion of dopamine terminals in nucleus accumbens has been shown in a number of studies to enhance opioid-induced motor activity (Kalivas and Bronson, 1985; Stinus et al., 1985; Churchill and Kalivas, 1992). Whether similar interactions occur between nucleus accumbens opioids and dopamine circuits in NSIA remains to be evaluated.

In summary, we demonstrate that although chronic morphine treatment results in tolerance to morphine antinociception, paininduced antinociception is unchanged. The reliance on nucleus accumbens opioid circuitry is modified, whereas the dependence on nucleus accumbens nicotinic and dopamine receptors remains. The correlation between the antinociception and nucleus accumbens dopamine release in either morphine naïve or morphinetolerant rats points to dopamine as a key neurotransmitter for production of antinociception. These findings suggest that a supraspinal, dopamine-mediated pain modulation system exists that might be effective in the management of intractable pain in patients tolerant to opioid analgesics.

\section{REFERENCES}

Ableitner A, Schulz R (1992) Neuroanatomical sites mediating the central actions of beta-endorphin as mapped by changes in glucose utilization: involvement of mu opioid receptors. J Pharmacol Exp Ther 262:415-423.

Ahn DK, Kim YS, Park JS (1998) Central NO is involved in the antinociceptive action of intracisternal antidepressants in freely moving rats. Neurosci Lett 243:105-108.

Altier N, Stewart J (1998) Dopamine receptor antagonists in the nucleus accumbens attenuate analgesia induced by ventral tegmental area substance $\mathrm{P}$ or morphine and by nucleus accumbens amphetamine. J Pharmacol Exp Ther 285:208-215.

Altier N, Stewart J (1999) The role of dopamine in the nucleus accumbens in analgesia. Life Sci 65:2269-2287.

Badiani A, Leone P, Stewart J (1995) Intra-VTA injections of the muopioid antagonist CTOP enhance locomotor activity. Brain Res 690:112-116.

Banks D, Kuriakose M, Matthews B (1992) Modulation by peripheral conditioning stimuli of the responses of trigeminal brain stem neurones and of the jaw opening reflex to tooth pulp stimulation in chronically prepared, anaesthetized cats. Exp Physiol 77:343-349.

Belforte JE, Barcelo AC, Pazo JH (2001) Striatal modulation of the jaw opening reflex. Brain Res 891:138-147.

Bodnar RJ, Glass MJ, Ragnauth A, Cooper ML (1995) General, mu and kappa opioid antagonists in the nucleus accumbens alter food intake under deprivation, glucoprivic and palatable conditions. Brain Res 700:205-212.

Borg PJ, Taylor DA (1997) Involvement of mu- and delta-opioid receptors in the effects of systemic and locally perfused morphine on extracellular levels of dopamine, DOPAC and HVA in the nucleus accumbens of the halothane-anaesthetized rat. Naunyn Schmiedebergs Arch Pharmacol 355:582-588.

Borgland SL (2001) Acute opioid receptor desensitization and tolerance: is there a link? Clin Exp Pharmacol Physiol 28:147-154.

Buelke-Sam J, Holson JF, Bazare JJ, Young JF (1978) Comparative stability of physiological parameters during sustained anesthesia in rats. Lab Anim Sci 28:157-162.

Caine SB, Heinrichs SC, Coffin VL, Koob GF (1995) Effects of the dopamine D-1 antagonist SCH 23390 microinjected into the accumbens, amygdala or striatum on cocaine self-administration in the rat. Brain Res 692:47-56.

Chiang CY, Dostrovsky JO, Sessle BJ (1990) Role of anterior pretectal nucleus in somatosensory cortical descending modulation of jawopening reflex in rats. Brain Res 515:219-226.

Chiang CY, Dostrovsky JO, Sessle BJ (1991) Periaqueductal gray matter and nucleus raphe magnus involvement in anterior pretectal nucleusinduced inhibition of jaw-opening reflex in rats. Brain Res 544:71-78.

Christie MJ, Trisdikoon P, Chesher GB (1982) Tolerance and cross tolerance with morphine resulting from physiological release of endogenous opiates. Life Sci 31:839-845.

Churchill L, Kalivas PW (1992) Dopamine depletion produces augmented behavioral responses to a mu-, but not a delta-opioid receptor agonist in the nucleus accumbens: lack of a role for receptor upregulation. Synapse 11:47-57.

Devine DP, Leone P, Wise RA (1993) Mesolimbic dopamine neurotransmission is increased by administration of mu-opioid receptor antagonists. Eur J Pharmacol 243:55-64.

Dill RE, Costa E (1977) Behavioural dissociation of the enkephalinergic systems of nucleus accumbens and nucleus caudatus. Neuropharmacology 16:323-326.

Gear RW, Levine JD (1995) Antinociception produced by an ascending spino-supraspinal pathway. J Neurosci 15:3154-3161.

Gear RW, Aley KO, Levine JD (1999) Pain-induced analgesia mediated by mesolimbic reward circuits. J Neurosci 19:7175-7181.

Girardot MN, Holloway FA (1984) Intermittent cold water stressanalgesia in rats: cross-tolerance to morphine. Pharmacol Biochem Behav 20:631-633.

Gold LH, Stinus L, Inturrisi CE, Koob GF (1994) Prolonged tolerance, dependence and abstinence following subcutaneous morphine pellet implantation in the rat. Eur J Pharmacol 253:45-51.

Harrison LM, Kastin AJ, Zadina JE (1998) Opiate tolerance and dependence: receptors, G-proteins, and antiopiates. Peptides 19:1603-1630.

Heyman JS, Jiang Q, Rothman RB, Mosberg HI, Porreca F (1989) Modulation of mu-mediated antinociception by delta agonists: characterization with antagonists. Eur J Pharmacol 169:43-52.

Horan P, Taylor J, Yamamura HI, Porreca F (1992) Extremely longlasting antagonistic actions of nor-binaltorphimine (nor-BNI) in the mouse tail-flick test. J Pharmacol Exp Ther 260:1237-1243.

Kalivas PW, Bronson M (1985) Mesolimbic dopamine lesions produce an augmented behavioral response to enkephalin. Neuropharmacology 24:931-936.

Kalivas PW, Churchill L, Klitenick MA (1993) The circuitry mediating the translation of motivational stimuli into adaptive motor responses. In: Limbic motor circuits and neuropsychiatry (Kalivas PW, Barnes CD, eds), pp 237-287. Boca Raton, FL: CRC.

Kelley AE, Bless EP, Swanson CJ (1996) Investigation of the effects of opiate antagonists infused into the nucleus accumbens on feeding and sucrose drinking in rats. J Pharmacol Exp Ther 278:1499-1507.

Lewis JW, Sherman JE, Liebeskind JC (1981) Opioid and non-opioid stress analgesia: assessment of tolerance and cross-tolerance with morphine. J Neurosci 1:358-363.

Loh HH, Liu HC, Cavalli A, Yang W, Chen YF, Wei LN (1998) mu Opioid receptor knockout in mice: effects on ligand-induced analgesia and morphine lethality. Brain Res Mol Brain Res 54:321-326.

Maisonneuve IM, Warner LM, Glick SD (2001) Biphasic dose-related effects of morphine on dopamine release. Drug Alcohol Depend 65:55-63.

Mason P, Strassman A, Maciewicz R (1985) Is the jaw-opening reflex a valid model of pain? Brain Res 357:137-146.

Matthes HW, Smadja C, Valverde O, Vonesch JL, Foutz AS, Boudinot E, Denavit-Saubié M, Severini C, Negri L, Roques BP, Maldonado R, Kieffer BL (1998) Activity of the $\delta$-opioid receptor is partially reduced, whereas activity of the $\kappa$-receptor is maintained in mice lacking the $\mu$-receptor. J Neurosci 18:7285-7295.

Moses J, Loucks JA, Watson HL, Matuszewich L, Hull EM (1995) Dopaminergic drugs in the medial preoptic area and nucleus accumbens: effects on motor activity, sexual motivation, and sexual performance. Pharmacol Biochem Behav 51:681-686.

Negri L, Improta G, Lattanzi R, Potenza RL, Luchetti F, Melchiorri P (1995) Interaction between the mu-agonist dermorphin and the deltaagonist [D-Ala2, Glu4]deltorphin in supraspinal antinociception and delta-opioid receptor binding. Br J Pharmacol 116:2931-2938.

Okamura H, Murakami T, Yokoyama C, Nakamura T, Ibata Y (1997) Self-injurious behavior and dopaminergic neuron system in neonata 6-hydroxydopamine-lesioned rat: 2. Intracerebral microinjection of dopamine agonists and antagonists. J Pharmacol Exp Ther 280:1031-1037.

Paxinos G, Watson C (1986) The rat brain in stereotaxic coordinates. New York: Academic.

Porreca F, Heyman JS, Mosberg HI, Omnaas JR, Vaught JL (1987) Role of mu and delta receptors in the supraspinal and spinal analgesic effects of [D-Pen2, D-Pen5] enkephalin in the mouse. J Pharmacol Exp Ther 241:393-400.

Pothos E, Rada P, Mark GP, Hoebel BG (1991) Dopamine microdialysis in the nucleus accumbens during acute and chronic morphine, naloxone-precipitated withdrawal and clonidine treatment. Brain Res 566:348-350.

Rossetti ZL, Hmaidan Y, Gessa GL (1992) Marked inhibition of me- 
solimbic dopamine release: a common feature of ethanol, morphine, cocaine and amphetamine abstinence in rats. Eur J Pharmacol 221:227-234

Schmidt BL, Tambeli C, Gear RW, Levine JD (2001) Nicotine withdrawal hyperalgesia and opioid-mediated analgesia depend on nicotine receptors in nucleus accumbens. Neuroscience 126:129-136.

Schmidt BL, Tambeli CH, Levine JD, Gear RW (2002) $\mu / \delta$ Cooperativity and opposing $\kappa$-opioid effects in nucleus accumbens-mediated antinociception in the rat. Eur J Neurosci 15:861-868.

Spanagel R, Almeida OF, Shippenberg TS (1994) Evidence that norbinaltorphimine can function as an antagonist at multiple opioid receptor subtypes. Eur J Pharmacol 264:157-162.

Stinus L, Winnock M, Kelley AE (1985) Chronic neuroleptic treatment and mesolimbic dopamine denervation induce behavioural supersensitivity to opiates. Psychopharmacology (Berl) 85:323-328.

Stinus L, Cador M, Le Moal M (1992) Interaction between endogenous opioids and dopamine within the nucleus accumbens. Ann NY Acad Sci $654: 254-273$

Takeda M, Tanimoto T, Ojima K, Matsumoto S (1998) Suppressive effect of vagal afferents on the activity of the trigeminal spinal neurons related to the jaw-opening reflex in rats: involvement of the endogenous opioid system. Brain Res Bull 47:49-56.

Wettstein JG, Grouhel A (1996) Opioid antagonist profile of SC norbinaltorphimine in the formalin paw assay. Pharmacol Biochem Behav 53:411-416.

Williams JT, Christie MJ, Manzoni O (2001) Cellular and synaptic adaptations mediating opioid dependence. Physiol Rev 81:299-343.

Yoburn BC, Chen J, Huang T, Inturrisi CE (1985) Pharmacokinetics and pharmacodynamics of subcutaneous morphine pellets in the rat. J Pharmacol Exp Ther 235:282-286.

Yu LC, Han JS (1990) The neural pathway from nucleus accumbens to amygdala in morphine analgesia of the rabbit. Sheng Li Xue Bao 42:277-283

Zhang S, Tang JS, Yuan B, Jia H (1998) Inhibitory effects of electrical stimulation of ventrolateral orbital cortex on the rat jaw-opening reflex. Brain Res 813:359-366.

Zhang S, Tang JS, Yuan B, Jia H (1999) Electrically evoked inhibitory effects of the nucleus submedius on the jaw-opening reflex are mediated by ventrolateral orbital cortex and periaqueductal gray matter in the rat. Neuroscience 92:867-875. 